Revista de la red interuniversitaria de estudios sobre las literaturas rioplatenses contemporáneas en Francia

$12 \mid 2015$

Prodigios borgeanos: ficciones, historias, teologías

\title{
Prodigios borgeanos : ficciones, historias, teologías
}

Mariana Di Ció, Teresa Orecchia Havas y Marta Waldegaray

\section{OpenEdition}

\section{Journals}

\section{Edición electrónica}

URL: http://journals.openedition.org/lirico/2020

DOI: $10.4000 /$ lirico.2020

ISSN: 2262-8339

Editor

Réseau interuniversitaire d'étude des littératures contemporaines du Río de la Plata

\section{Referencia electrónica}

Mariana Di Ció, Teresa Orecchia Havas y Marta Waldegaray, "

Prodigios borgeanos : ficciones, historias, teologías », Cuadernos LIRICO [En línea], 12 | 2015, Publicado el 23 enero 2015, consultado el 22 septiembre 2020. URL : http://journals.openedition.org/lirico/2020 ; DOI : https://doi.org/10.4000/lirico.2020

Este documento fue generado automáticamente el 22 septiembre 2020

\section{(c)}

Cuadernos LIRICO está distribuido bajo una Licencia Creative Commons Atribución-NoComercialSinDerivar 4.0 Internacional. 


\title{
Prodigios borgeanos : ficciones, historias, teologías
}

\author{
Mariana Di Ció, Teresa Orecchia Havas y Marta Waldegaray
}

Este número deCuadernos LIRICO

se propone realizar un nuevo aporte a los estudios sobre Borges y su obra en coincidencia con el temario propuesto en el campo de la literatura hispanoamericana para la sesión 2015 del concurso de Agrégation. En este sentido, puesto que el objetivo se articula en torno a una ambición crítica que no desdeña el horizonte pedagógico, hemos pensado en abarcar tanto temas de estética y poética como de fundamentos epistemológicos y contextos histórico-culturales, sin descuidar las relaciones de unos textos con otros, tanto dentro del corpus elegido ( FiccionesyEl hacedor) como hacia fuera de él, en particular respecto a las narraciones de El Aleph

. Aun dentro de este marco relativamente restricto, nuestra empresa no era sencilla, tratándose de un autor al que se percibe hoy como una suerte de epítome o emblema de toda la literatura, y de una obra que ha sido explorada con ahínco creciente en el último medio siglo. Se trataba de incorporar perspectivas analíticas originales en un momento en que todo parece haber sido escrito, e incluso ya más de una vez, sobre Borges ; se trataba también de evitar el riesgo o la tentación de " monumentalizar » una vez más los textos y de soslayar el efecto de saturación que producen el « aggiornamento » y la reiteración de las tradiciones críticas.

Repasemos brevemente algunos hitos de ese mapa de lecturas borgeanas que permanece como marco de cada nuevo intento bibliográfico. Sabemos bien que la obra de Borges ha sido discutida con vehemencia ya desde los años treinta, aun antes de la publicación de su primer libro de ficción,

Historia universal de la infamia

(1935). Pero en la década del cincuenta aparece en Argentina, dentro del ámbito de la crítica científica universitaria, el primer libro que desde el discurso académico la consagra en tanto objeto de estudio erudito, La expresión de la irrealidad en la obra de Jorge Luis Borges 
, de Ana María Barrenechea (1957). Ese ensayo inaugura una tradición crítica, la del examen analítico de los textos, que no ha cesado de prolongarse y de multiplicarse exponencialmente hasta nuestros días, aun cuando la época en que el escritor ya es reconocido a nivel internacional, los años sesenta, resulta paradójicamente el momento en que el valor de Borges se discute más acerbamente en su patria en relación no sólo con el sentido de su literatura sino con el futuro de la literatura misma. En las décadas siguientes en cambio, la coincidencia de los planteos teóricos deudores del formalismo,

del estructuralismo y del New Criticism con el enorme reservorio de ideas sobre la literatura que destilan sus escritos, así como la inscripción cada vez más consolidada del autor como un « clásico » de las letras locales (y universales) y el reconocimiento de las sutilezas y desafíos de su estética aportan un giro decisivo. En lo sucesivo se pasará de un debate que se enfrenta a los textos y que eventualmente va dirigido contra Borges, a una etapa en la que ya no se polemiza sobre la colocación del corpus en la producción cultural argentina ni contra la intencionalidad del proyecto creador, sino que se comienza a estudiar incesantemente una práctica de la escritura que se descubre cada vez más susceptible de comentario erudito.

Los jalones de este recorrido de cuatro décadas en términos de las interpretaciones de la obra son bien conocidos. No los recapitularemos nuevamente ahora ; sólo nos limitaremos a recordar que, indudablemente, los libros de Sylvia Molloy (

Lasletras de Borges, 1979) y Beatriz Sarlo (Borges, un escritor en las orillas

, 1993) marcan hitos por los que transitará toda la crítica posterior. Quisiéramos señalar igualmente que una inflexión notable en lo que ya es un gran caudal hermenéutico se produce en los noventa con la aparición de estudios que en lugar de especular sobre las características estilísticas, retóricas o intertextuales, y las implicaciones gnoseológicas y filosóficas del discurso literario borgeano se aplican a establecer las relaciones de ese discurso con sus contextos socio-históricos, a probar sus vinculaciones con una realidad representada, alegorizada o secreta (Daniel Balderston, $i$

Fuera de contexto ?, 1993 yRealidades y simulacros

, 2000). Del mismo modo, surge en los últimos años un interés renovado por la biografía de Borges y por la construcción de su figura de autor que tiene lazos con el examen de sus estrategias dentro del campo literario (Annick Louis,

Jorge Luis Borges : oeuvre et manoeuvres

, 1997). A una crítica que razonaba su propia fascinación por los textos y que ponía en perspectiva sus lecturas acudiendo al acervo de la biblioteca universal, o al estudio minucioso de los procedimientos (Michel Lafon,

Borges ou la réécriture

, 1990), se suma entonces una línea de acercamiento diferente, interesada en las « circunstancias » que ingresan transfiguradas en la creación, desde el proyecto consciente del escritor hasta la huella de sus pentimentos

, desde sus tomas de posición ocultas en los textos hasta el estudio de los soportes editoriales que los sirven. Pasamos del Borges que la crítica postulaba como legible sólo mediante el desciframiento de las sofisticadas arquitecturas de su imaginario y de los ejercicios metamórficos de su poética a un Borges lúcido, calculador, artesano de sí mismo e ingeniero de su propia fama. 
De modo que esa obra que había podido ser alternativamente objeto de incomprensión, de admiración o de reticencia, se fue convirtiendo poco a poco en lo que Borges mismo auguraba en 1945 bajo la forma de un voto, el deseo de fraguar un texto que sea « todo para todos », una obra que representara toda la literatura y pudiera ser leída en una cantidad infinita de modulaciones 1 .

Veamos ahora más de cerca las otras implicaciones del desafío a los lugares y a la ética del lector que contienen los textos de nuestro escritor. En su breve artículo « Sobre los

Otras inquisiciones, 1952), Borges se interroga acerca de la condición de serun clásico

. Asociando el adjetivo latinoclassisa la idea deorden

, pero sin dejar de destacar su sentido marino primero deflota

, reúne en su reflexión lo clásico con lo verdadero, con lo que uno « cree verdadero » y propone por lo tanto que un libro clásico es un libro cuya lectura « reclama un acto de fe » (OC 1974 : 772 y 773). Presenta su tesis de la siguiente manera : « Clásico es aquel libro que una nación o un grupo de naciones o el largo tiempo han decidido leer como si en sus páginas todo fuera deliberado, fatal, profundo como el cosmos y capaz de interpretaciones sin término. Previsiblemente, esas decisiones varían. » Y concluye diciendo : «Una preferencia bien puede ser una superstición. » (OC : 773). La obra clásica queda así solidarizada en su reflexión con lo sagrado (la fe, la superstición), con aquello que se recorta y distancia de lo profano, aunque no de manera universal, sino contingente (Borges señala el perímetro de lo nacional) y pragmática, puesto que, en su opinión, lo clásico es menos una condición o un « mérito » que una categoría adjudicable. Es una decisión de lectura que -según parece pensar- confiere seguridad al lector. Como puede observarse, el escritor cuestiona la idea atemporal y universalista de lo clásico, y acaso también, de lo canónico. La pregunta que puede formularse desde esta perspectiva borgeana que desvirtúa la idea establecida acerca de los cánones literarios es entonces ¿cómo seguir leyendo hoy al propio Borges, el gran clásico de la literatura argentina? ¿Qué nueva decisión de lectura nos sugiere hoy su obra? ¿Cómo forzar la "misteriosa lealtad" que induce a la consagración de una obra o de un autor? Con resonancias bajtinianas, Borges propone una pista para dilucidar estos interrogantes al afirmar que la vigencia de lo clásico se deteriora con el tiempo y que en el origen de ese deterioro está el desgaste de los medios. Escribe : « los medios deben constantemente variar [...]. Se gastan a medida que los reconoce el lector. [...] Cada cual descree de su arte y de sus artificios ». Si seguimos este razonamiento, así como en opinión de Borges la erosión de los procedimientos formales invitaría al escritor a modificarlos, el lector debería también proponerse el desafío intelectual de alterar su posición de lectura, esto es, de poner en cuestionamiento o renovar críticamente su perspectiva. Modificar el ángulo de lectura significa fundamentalmente orientar de otra manera qué

leer en la obra de un autor, y esto, sin perder de vista que estas variaciones implican valoraciones literarias que no son nunca ajenas a determinaciones de interés subjetivo, cultural, institucional. Así por ejemplo, en su prólogo a El hacedor 
(1960), Borges esboza una filiación autolegitimante en materia literaria. En el segundo y tercer párrafos de este breve texto afirma la dignidad literaria de Leopoldo Lugones y en el diálogo ficticio que con él parece entablar se posiciona como su heredero : « mañana [...] será justo afirmar que yo le he traído este libro y que usted lo ha aceptado. » (779). En los tres párrafos de este breve prólogo dedicado a Lugones, Borges remonta el tiempo para erigir su estirpe literaria, lo cual entraña una elección políticocultural. La primera frase del prólogo divide aguas. El silencio de la Biblioteca le permite dejar afuera « los rumores de la plaza » popular y peronista (OC : 779). Anteriormente, en « El escritor argentino y la tradición

", Borges había cuestionado el costumbrismo argentino y la defensa del color local propiciada por el nacionalismo (peronista) de mediados del siglo XX. Y a principios de los años 30, en « La poesía gauchesca » (

\section{Discusión}

, 1932), había afirmado a contrapelo de lo establecido que la materia temática y la procedencia de un escritor no son los elementos esenciales con los cuales se deba definir un género literario (OC : 179). Estos pocos ejemplos nos muestran una manera particular de interpretar el pasado en Borges. Borges es un hacedor cuyo hacer consiste en deshacer las ideas recibidas, en desmontarlas, para proponer otra manera de leer, transgresiva, hacia atrás ; para inscribirse en otra tradición cultural ; y para fundir por ejemplo la prosa con el verso. Si como postulaba Italo Calvino, un texto se lee y un clásicosiempre esre

leído, Borges es clásico porque su escritura y sus propuestas siempre estimulan la relectura de la literatura y de la tradición cultural argentinas.

Los ensayos que se recogen aquí parten de diferentes ángulos de lectura. Provenientes de circuitos académicos diferentes (Francia, Argentina, Estados Unidos), sus autores han orientado el análisis de

Ficcionesy deEl hacedor

hacia perspectivas críticas propias de cada ámbito buscando siempre renovar las problemáticas. Los mencionaremos ahora según el orden alfabético de autores, tal como aparecen insertados en este volumen.

Daniel Balderston, que abre la serie de contribuciones, continúa su paciente estudio genético de los textos borgeanos en su artículo « Senderos que se bifurcan : dos manuscritos de un cuento de Borges » analizando dos manuscritos de «El jardín de senderos que se bifurcan ", de diferente riqueza de variaciones. El primero de ellos contiene muchas variantes, mientras que el segundo es una copia en limpio que brinda sin embargo interesante material genético. En aquél la hoja muestra la " pululación » de posibilidades de la que trata el texto ; la escritura duplica la incertidumbre que informa el discurso y se realiza como bifurcación y simultaneidad, igualmente temas del relato. Su minucioso trabajo se completa con la reproducción de una de las páginas estudiadas.

Con el artículo de Mariela Blanco, « Ficciones de la conjetura. La nación como invención en Borges ", cambiamos de método y de enfoque. La autora analiza el sustrato ideológico de las marcas de la historia en

Ficciones 
y, más específicamente, en dos de los textos del volumen : « Funes el memorioso » y «La forma de la espada ». Partiendo de la constatación ya conocida de las imprecisiones cronotópicas borgeanas, así como de la manera indirecta de aludir a lo histórico, sostiene que los dispositivos narrativos de simulación en los textos de Borges explicitan no sólo el pacto ficcional con el lector, sino que también ponen en evidencia el carácter convencional de toda institución social. Blanco estudia así en este artículo la doble condición, imaginaria y narrativa, del dispositivo de lo nacional en tanto construcción simbólica de la modernidad. Las situaciones confusas y/o enigmáticas de no pocas de las tramas de los cuentos de Borges, así como las marcas textuales de verosimilitud histórica (los nombres propios, las fechas, los espacios) en

Ficcionesson utilizadas de maneradistópica

corroyendo tanto la dimensión histórica de los textos como el sentido hegemónico de la nación. Lo nacional, que aparece tempranamente en los textos de Borges, se enfrenta entonces polémicamente con el discurso nacionalista de mediados del siglo XX, aquél que en el contexto mundial de entreguerras, y en la Argentina de los años 30 en adelante, compuso un modelo fuerte de estado nacional.

Mercedes Blanco trabaja a su vez sobre un aspecto que requiere la solvencia propia de las lecturas eruditas. Se trata de la presencia de la teología en tanto subtexto y temática en las narraciones de Borges. En este importante artículo, « El teólogo enmascarado

(Teólogos y sectarios en

FiccionesyEl Aleph

) », que renueva la perspectiva tradicional sobre las ficciones « fantásticas » o de la « irrealidad», se parte de las tesis sobre la relatividad histórica del pensamiento a las que Borges suscribe a fin de señalar que en ellas se desdibujan paradójicamente los límites entre filosofía y teología. Tal impregnación de lo teológico en los relatos tiene según la autora motivaciones eminentemente literarias. El discurso teológico, que introduce un plano transcendente sin cambiar nada en el plano empírico de los hechos narrados, inyecta misterio sin contradecir la lógica de los sucesos, autoriza lo fantástico y facilita la reunión de lo maravilloso con lo verosímil, una poética que el autor explora en un grupo esencial de sus narraciones. Así se combinan el placer de lo prodigioso con la actitud irreverente o escéptica. Entre las técnicas del relato borgeano deudoras de esta inspiración teológica el artículo se centra en particular en la invención de personajes « teólogos », sectarios y heresiarcas en los cuentos de

FiccionesyEl Aleph

, personajes todos cuyas acciones y ocupaciones pueden leerse como figuraciones de la creación literaria donde se indica que el pensamiento y la creación no son separables del destino del hombre. 
Emparentada con esta problemática se encuentra la colaboración siguiente, « Civilizar el infinito : el milagro, la revelación y lo sublime en la obra de Jorge Luis Borges ». Jorge

Brioso se interesa aquí por lo que el crítico denomina « filosofía de la creación » en Borges, consistente en la preferencia del autor por las explicaciones racionales y los modelos narrativos de tipo analítico como el género policial clásico. Brioso observa en este perfil borgeano del acto creativo algunas grietas compositivas en la narrativa de Borges que tienen que ver con aspectos que escapan al esquema racional. Se trata del milagro, el infinito, la revelación, la emoción y los afectos. En el artículo se analiza cómo Borges intenta domesticar racionalmente el desconcierto que estas instancias generadoras de historias entrañan. Brioso sostiene su hipótesis a través del análisis de textos pertenecientes a

Historia de la eternidad,Ficciones,El Aleph,Otras inquisiciones.

Tomando como punto de partida la producción de los años 20 y 30, Magdalena Cámpora estudia en « Borges y el idioma de los franceses » la relación paradójica que une a

Borges con el francés y, por extensión, con la literatura francesa. Al contextualizar y matizar la tan mentada francofobia de Borges en un país tradicionalmente francófilo, la reflexión de Cámpora permite iluminar el modo en que éste desplaza intencionalmente al francés como modelo de lengua. Mediante un documentado análisis, Cámpora esclarece el modo en que, a pesar de su flagrante omisión, el francés actúa como rival tácito en las consideraciones de Borges sobre la riqueza léxica, el uso de americanismos o regionalismos, la economía verbal o el tono de lo que llamará « la heterogénea lengua vernácula de charla porteña ». Además de presentar un marco contextual para la reflexión sobre « el idioma de los argentinos » y de sentar las bases para la explicación lingüística de los candidatos a la Agrégation, el artículo plantea la ambigüedad de Borges frente al francés no solo como una estrategia de diferenciación y de posicionamiento literario, sino también como un modo de intervenir en la querella sobre la lengua, y de establecer un contrapunto sutilmente agónico con la figura y las posiciones enarboladas por Victoria Ocampo.

En continuidad con esta reflexión sobre la lengua, la cuestión de la traducción en tanto gesto esencial y contradictorio en la trayectoria intelectual de Borges es hoy un campo de hipótesis fértil para la tarea de los investigadores argentinos. El artículo de Delfina Muschietti " Contra el propio canon : Borges en el Laboratorio de Traducción », enfoca precisamente textos laterales de Borges (prólogos, reseñas, conferencias) en los que el escritor argumenta sobre la traducción, aparece como un lector de traducciones o escribe desde el lugar de un traductor. El objetivo de Muschietti es poner de relieve las contradicciones entre las bien conocidas posiciones de Borges sobre las nociones de autor o de texto original y lo que se lee en esos textos, que en ocasiones preconizan más la literalidad que la versión libre o expresan una concepción romántica de la poesía en la cual el lenguaje es devuelto a su fuente originaria. La propuesta de la autora está sólidamente enmarcada en una serie de premisas teóricas que ella misma ha elaborado a partir de las ideas de Benjamin y de Agamben, y que giran en torno a los conceptos de

« mapa rítmico », « partitura flotante » o aun " plataforma flotante », a través de los cuales su trabajo aspira a transformar los parámetros habituales de la teoría de la 
Siguiendo otra lógica de variaciones, Pablo Martín Ruiz revisa el modo en que Borges continúa, en su ficción, discusiones de poética clásica, particularmente en lo que se refiere a la causalidad narrativa y la mímesis. En su artículo « De Almotásim a Abenjacán : dinámicas entre composición y lectura en la ficción de Borges ", Ruiz rastrea en la ficción borgeana ecos y modulaciones varias de las discusiones entre platónicos y aristotélicos, o entre inspirados y razonadores, a los que entiende como jalones de una construcción progresiva de una poética de la ficción, cuyo punto de partida sería « El acercamiento a Almotásim », de 1936. La reflexión está articulada en torno a la figura del « hacedor », de la que se desprende, para Ruiz, un relato de composición a la manera de Poe, pero también, cuestión quizás más importante, una teoría borgeana de la composición que hace eco al artículo de Jorge Brioso. Al referirse al mito del Borges lector como modo de construcción de una figura de autor, Ruiz se detiene también en la lectura como contracara de la escritura, analizando el modo en que Borges piensa la lectura y la incluye en su escritura. Es así que, en textos como « Pierre Menard » o « Herbert Quain », Borges incluye modelos de lectura específicos que actúan, según Ruiz, como matrices o generadores de escritura, pero también, como modo silencioso de polemizar con las vanguardias.

Por último, Sebastián Urli, colocándose de lleno en esta línea del interés actual por las figuras de autor, presenta en su artículo «"De un yo plural y de una sola sombra" : autofiguración y retrato en

El hacedor

» un análisis del incesante proceso de autofiguración que Borges desarrolla en ciertos textos de

El hacedor

. Basándose en la literatura crítica reciente dedicada a ese tema, conjetura que hay al menos dos formas de tal proceso. Por un lado, una figura que se elabora con datos biográficos (biografemas) del Borges real. Por otro, una figura articulada a partir de la proyección de biografemas en otros sujetos distintos e incluso lejanos en tiempo y espacio, produciendo retratos de los otros que implican una prolongación y a la vez un límite para la representación del yo.

Quisiéramos por último terminar este recorrido evocando la figura tutelar de Michel Lafon (1954-2014), hispanista, especialista de Borges, profesor y traductor de la literatura argentina contemporánea a la que iluminó en tantos artículos y libros de sutil inteligencia, con cuya desaparición en 2014 se ha perdido uno de los más lúcidos investigadores franceses de las letras argentinas.

A él le dedicamos estos estudios. 


\section{NOTAS}

1.

En la entrevista « De la alta ambición en el arte » Borges declaraba que su máxima ambición era « escribir un libro, un capítulo, una página, un párrafo, que sea todo para todos los hombres,

como el Apóstol» (

Textos recobrados (1931-1955), $2002: 152$ ).

Esta frase ha sido citada innumerable cantidad de veces por los comentadores de la obra.

2.

Clase dictada el 7 de diciembre de 1951 en el Colegio Libre de Estudios Superiores y publicada en 1955 en el nº 232 de la revista Sur. 